African Journal of Biomedical Research, Vol. 7 (2004); 79 - 83

ISSN 1119 - 5096 @ Ibadan Biomedical Communications Group

AdBD

Full Length Research Article

\title{
EFFECTS OF THREE CLASSES OF ALCOHOLIC BEVERAGES ON CHLOROQUINE ABSORPTION IN THE STOMACH AND INTESTINE OF RATS.
}

\author{
AJANI, O. C., EGHIANRUWA. K. I*. AND FAMAKINDE, S. A. \\ Department of Veterinary Physiology and Pharmacology, University of Ibadan, Nigeria.
}

\begin{abstract}
The effects of three different types of alcoholic beverages (beer, wine and gin) on the absorption of chloroquine in the stomach and intestine of rats were determined. The in situ loop method and in situ re-circulation technique were used to determine the absorption of chloroquine [CQ] in the stomach and intestine respectively. $52.50 \%$ of $C Q$ was absorbed from the stomach in the absence of alcoholic beverage in 30 minutes while $59.30 \%$ was absorbed from the intestine in one hour in the absence of alcoholic beverages.. Alcoholic beverages increased the amount of chloroquine absorbed in the following order; gin > wine > beer. The increases were higher in the stomach. While the percentage increases in absorption induced by alcoholic beverages in the stomach were 12.80, 25.62 and 37.50 for lager beer, wine and gin respectively, the corresponding values for the small intestine were 9.01, 20.13 and $33.24 \%$ for lager beer, wine and gin respectively. The consumption of alcoholic beverages both simultaneously or following the oral administration of $C Q$ does not reduce the amount of CQ absorbed and hence may not be the cause of drug failure.
\end{abstract}

Keywords: Absorption, Alcohol, Chloroquine, intestine, stomach.

*Author for correspondence.

\section{INTRODUCTION}

Chloroquine is the most widely used of the 4 - aminoquinoline antimalarial drugs (Spracklen, 1984). It also has antiinflammatory properties that have been used to an advantage in such diseases as rheumatoid arthritis and polymyositis (Day et, al 1982; Magnussen \& Olivarius, 1977) discoid and systemic lupus erythematosus (Olansky, 1982).

The resistance of malaria parasite especially Plasmodium falciparum to chloroquine has been reported by several workers [Charmont, 1981; Onori et al., 1982, Nieuwveid et al., 1982; Reickmann, 1983). The mechanism of resistance of malaria to chloroquine may be complex (Foote et al., 1990;) but refractoriness due to reduced bioavailability has not been ruled out (Herzog et al., 1982).
In Nigeria, a malaria endemic country, chloroquine is purchased easily over the counter. In most parts of Nigeria, the sale and consumption of alcoholic beverages is unrestricted. It is common to see people consuming alcoholic beverages concomitantly or soon after taking chloroquine tablets. The effects of alcohol on gastrointestinal function vary depending on the type of beverage and the level of ethanol in the beverage (Laurence et al., 1997; Ritchie, 1975; Tripathi, 1998). As far as can be determined, the effect of alcoholic beverages on the bioavailability of chloroquine from the entereal route is not known. This study was therefore undertaken to determine the effect of the three popular classes of alcoholic beverages in Nigeria on chloroquine absorption from the stomach and small intestine of rat. 


\section{MATERIALS AND METHODS}

Animals: Thirty albino rats were used in the study. They were of mixed age and sex, and weighed between 130 and $155 \mathrm{~g}$. Animals were kept in cages and fed commercially formulated mice cubes. Water was given ad libitum. Animals were fasted over night before the day of experiment but were given water.

Alcoholic Beverages: Three commonly available alcoholic beverages namely lager beer, wine and gin were used. The lager beer was the popular Star brand, which is brewed and bottled in Nigeria by Nigerian Breweries PLC. The alcoholic content of the beer was $5 \%$ per volume. The wine was the Carta Blanca brand that was imported into Nigeria from Germany. The quoted alcoholic content was $10 \%$ per volume. The gin contained $43 \%$ alcohol per volume. It was of the Cherry London Dry Gin brand that is blended and bottled in Nigeria by Stellan Industries [Nig] Ltd. The effect of each alcoholic beverage on absorption was studied in ten rats.

Drug: Chloroquine phosphate solution for injection was used for absorption studies. These were purchased over the counter in a local drug store. Preparations from four pharmaceutical companies were obtained and subjected to assay using chloroquine phosphate reference standard [obtained from Pharmatek Industrial Project Limited, Ilorin, Nigeria] to authenticate the amount of chloroquine phosphate base quoted by each company. The method of assay was as described in the United States Pharmacopoeia (1989). The preparations that were finally used in the study were those from manufacturers whose products passed the assay test.

Absorption Studies: Absorption studies were carried out simultaneously on the stomach and small intestine of each rat. Rats were anesthetized with $0.6 \mathrm{ml} / 100 \mathrm{~g}$ $25 \%$ urethane administered intraperitoneally.
Stomach: The in situ loop method described by Kimura et al (1981) was used. The stomach of anesthetized rat was opened and evacuated. The esophageal and pylorus ends were ligated. $4 \mathrm{ml}$ solution containing $20 \mathrm{mcg} \mathrm{ml}^{-1}$ of chloroquine phosphate base were held in the stomach for 30 minutes. After this period, the solution was withdrawn and the stomach washed with distilled water to obtain $10 \mathrm{ml}$ final solution. Following this, $4 \mathrm{ml}$ of an alcoholic beverage under study was held in the stomach for 15 minutes after which the beverage was withdrawn and the stomach washed. The absorption study of chloroquine was then repeated. The 15 minutes for holding alcoholic beverage was chosen from series of pilot experiments in which it was observed that animals die before the end of experiment if alcoholic beverage is applied for periods exceeding 15 minutes.

Intestine: The in situ re-circulation technique also described by Kimura et al (1981) was used. The small intestine was cannulated in the pylorus and ileo-caecal junctions. $40 \mathrm{ml}$ solution of chloroquine phosphate containing $20 \mathrm{mcg}$ of chloroquine phosphate base per $\mathrm{ml}$ was kept at $37^{\circ} \mathrm{C}$ in a water bath. This solution was re-circulated through the intestine for one hour at $5 \mathrm{ml}$ $\min ^{-1}$ using a peristaltic pump. After one hour the solution was withdrawn and the intestinal lumen washed with distilled water. The washings and the re-circulated solution were combined and allowed to reach $100 \mathrm{ml}$. Following this, $40 \mathrm{ml}$ of an alcoholic beverage under study was re-circulated through the intestine at $5 \mathrm{ml} \mathrm{min}^{-1}$ for 15 minutes. The alcoholic beverage was withdrawn after the period and the intestine washed. The absorption study of chloroquine was then repeated. The amount of chloroquine in the final solutions from the stomach and intestine before and after the application of alcoholic beverages were determined in a spectrophotometer using PYE Unican ASP8-400 UV/Visible spectrophotometer at the wavelength of $343 \mathrm{nM}$ after chemical extraction using the method described in the United State Pharmacopoeia (1989). 
Statistical Analysis: The amount of chloroquine disappearing from the lumen, which is the difference between the amounts of the drug in the initial and final solutions, was regarded as the amount absorbed. The means of absorption rates and standard deviations of the means were calculated for all trials. The differences in the means $[ \pm$ SEM] in absorption rates before and after application of alcoholic beverages were assessed using Students t- test. A P-value of $P<0.05$ was taken as significant.

\section{RESULTS}

Results are presented in Table1. $52.50 \%$ of chloroquine was absorbed from the stomach after 30 minutes and $59.30 \%$ from the intestine after 1 hour. The rate of absorption increased in the stomach and small intestine after the application of alcoholic beverages to these segments. The rates of increase in absorption were dependent on the level of alcohol in the beverages with lager beer causing the least and gin the most increase. The amount of chloroquine absorbed is higher in the intestine than in the stomach with or without alcoholic beverages but the percentage increases in the absorption of chloroquine was greater in the stomach than in the intestine following application of alcoholic beverages.

\section{DISCUSSION}

Alcoholic beverages enhanced the absorption of chloroquine from the GIT. The pharmacokinetic implication of this enhancement is increased bioavailability. The bioavailability of chloroquine in normal subjects was shown to be $87 \pm 16 \%$ [Frisk Holmberg et al., 1984; White, 1985]. The higher bioavailability figures given by these workers compared to the levels of absorption of $\mathrm{CQ}$ obtained from this study may be due to more sensitive methods and time between administration of the drug and estimation However, it is certain from this study that alcoholic beverages do increase the rate of absorption of orally administered $\mathrm{CQ}$. Although the mechanism of enhanced chloroquine absorption by alcoholic beverages was not determined in this study, ethanol is known to be rapidly absorbed from the stomach and small intestine and to cause vasodilatation more through central action than local. (Rall 1992). Increased perfusion of GIT is a factor known to enhance drug absorption (Tripathi, 1998). The increase in absorption induced by ethanol was higher in the stomach than in the intestine. While the percentage increases in absorption induced by alcoholic beverages in the stomach were 12.80, 25.62 and 37.50 for lager beer, wine and gin respectively, the corresponding values for the small intestine were 9.01, 20.13 and $33.24 \%$ for lager beer, wine and gin respectively. The differential rates of enhanced absorption cannot be explained from results of this study. However, ethanol is itself rapidly absorbed from the stomach [Ritchie, 1975; Laurence et al, 1997] followed by corresponding increase in vasodilatation.

Rapid absorption of ethanol from the stomach followed by additive sedative effect of the anesthetic agent may also be responsible for early deaths when alcoholic beverages were held in the stomach for more than 15 minutes.

\section{Table 1.}

Absorption of chloroquine in the stomach and intestine of rats before and after application of alcoholic beverages. Values are means $[n=10] \pm$ SEM.

\begin{tabular}{|l|l|l|l|l|}
\hline Events & Stomach & Intestine & \multicolumn{2}{|l|}{ Mean Increases [\%] From Normal } \\
\cline { 4 - 5 } & & & Stomach & Intestine \\
\hline Percent Absorption In The & 52.50 & 59.30 & NA & NA \\
Absence Of Alcoholic Beverage. & $\pm 4.21 \%$ & $\pm 4.89 \%$ & & \\
\hline Percent Absorption following & 65.30 & 68.31 & 12.80 & 9.01 \\
Application of Lager Beer & $\pm 4.97 \%$ & $\pm 4.05 \%$ & & \\
\hline Percent Absorption Following & 78.12 & 79.43 & 25.62 & 20.13 \\
Application Of Wine & $\pm 6.25 \%$ & $\pm 6.41 \%$ & & 33.24 \\
\hline Percent Absorption Following & 90.00 & 92.54 & 37.50 & \\
Application Of Gin & $\pm 7.35 \%$ & $\pm 7.54 \%$ & & \\
\hline
\end{tabular}

$N A=$ Not applicable. 
Concomitant intake of alcoholic beverages and oral chloroquine preparation may not induce the development of resistant strains of Plasmodium since the three alcoholic beverages studied increased the absorption of chloroquine from the GIT. The practice may even provide ethanol for the ethanol/alcohol oxidase system.

Becker et al., [1990] suggested that the ethanol/alcohol oxidase system might be of interest as a potential chemotherapeutic principle in malaria since acetaldehyde, a product of the system was shown to be parasiticidal. Hydrogen peroxide, another product of the system was also shown to play an important role in host defense mechanism. These authors showed that 8.7 $\mathrm{mM}$ [0.5\%] ethanol and $0.1 \mathrm{U}$ alcohol oxidase per $\mathrm{ml}$ of culture irreversibly damaged $95 \%$ of parasites.

Results from this study indicate that concomitant consumption of alcoholic beverages and oral administration of $\mathrm{CQ}$ tablets may aggravate the puritogenic effect of chloroquine since more chloroquine will be available for distribution to skin and skeletal muscle (Osifo, 1980; 1987).

Increased absorption of chloroquine by alcoholic beverages could enhance the appearance of ocular damage. Trojan (1982) reported the presence of ocular damage in 27 cases undergoing chloroquine prophylaxis of $300 \mathrm{mg}$ base per week. This situation could result from the concomitant intake of alcoholic beverages and oral chloroquine preparation at an otherwise normal dosage. There is a renewed call for the use of chloroquine in rheumatoid arthritis (Day, 1982). Olanskey (1982) advocated judicious daily dosage and regular ophthalmic follow up in the prolonged use of chloroquine in rheumatoid arthritis. Increased bioavailability of chloroquine due to concomitant intake of alcoholic beverages could make this otherwise judicious daily dosage toxic.

\section{REFERENCES}

Becker, K., Hopkins, T. R., and Schirmer, R. H. [1990]. Antimalarial activity of the ethanol/alcohol oxidase system in vitro. Free Radic. Res. Commun. 9 (1): 33 - 38.
Charmont, G. (1981). Current news in prophylaxis and malaria treatment. Bull. Soc. Path. Exot Filiales. 74(6). 595-599.

Day, R.O., Sambrook, P., Champion, C.D \& Graham, G.G. (1988) Antimalarials in rheumatoid diseases. Aust-NZ. J. Med. 12(6). 645-649.

Foote, S. J., Kyle, D. E., Martin, R. K., Oduola, A. M., Forsyth, K., Kemp, D. J. and Cowman, A. F. (1990). Several alleles of the multidrug - resistance gene are closely linked to chloroquine resistance in Plasmodium falciparum. Nature. 343 (6272): $225-228$.

Frisk-Holmberg, M., Berggvist, Y; Termond, E; and Domeji- Nyberg B (1985). The single-dose kinetics of chloroquine and its major metabolite desrnetlyl-chloroquine in healthy subjects. Eur. J. Chin. Pharmacol. 26: 521 - 530.

Herzog, C., Ellis, C.J., Innes J.A. \& Fletchs, K.A (1982). Possible role of drug malabsorption in recrudescence of falciparum malaria. Lancet. 2(8308) 1158.

Kimura, T., Kim, K.S., Sezaki, H. (1981) Effect of taurine on drug absorption omitted from rat gastrointestinal tract. J. Pharmacolobio-Dyn. 4: 35-41.

Laurence, D. R., Bennett, P. N., and Brown, M. J. [1997]. Clinical Pharmacology [8 $8^{\text {th }}$ Edition]. Churchill Livingstone, New York. Pp 166-177.

Magnussen, I and Olivaruis, B (1977). Cardiomyopathy after chloroquine treatment. Acta medica Scandinavia 202(5): 429-431.

Nieuwveid, R.W., Halkett, J.A and Spracklen , F.A. Drug - resistant malaria in Africa, A case report and review of the problem and treatment. S. Afr. Med. J. 62(6): 173-175.

Olansky. A.J. (1982). Antimalarials and ophthalmologic safety. J. Am. Acad. Dermatol. 6(1). 19-23.

Onori E, Payne, D., Grab, B., Horst, H. I., Almeida Franco, J. Joia, H. (1982). Incipient resistance of plasmodium falaparum to chloroquine among a semi immune population of the united Republic of Tanzania. I. Results of in vivo \& in vitro studies \& of ophthalmic survey. Bull WHO 60(1): 77-87.

Osifo, N.G. (1980) Chloroquine pharmacokinetics in tissues of pyrogentreated rats and implications for chloroquine- 
related pruritus. Res. Comm.. chem.. Pathol. Pharmacol. 30: 419-430.

Osifo, N.G. (1987). An animal model of chloroquine-induced pruritus. Nig. J Physiolo. Sc. 3: 31-35.

Peeters, P.A., de Leest, K., Eling, W. M. and Crommelin, D. J. [1989]. Chloroquine levels after administration of the liposomeencepsulated drug in relation to therapy of murine malaria. Pharm. Res. 6[9]: 787 798.

Rieckmann, K.H. (1983). Falciparum malaria: the urgent need for safe \& effective drugs Annu. Rev. Med. 34: 321-335.

Rall T. W. (1992). Hypnotics and sedatives; Ethanol. In Goodman and Gilman's Pharmacological Basis of Therapeutics. Gilman AG, Rall TW, Nies AS and Taylor P (eds). New York. McGrall-Hill Inc.
Ritchie, M. J. [1975]. The aliphatic alcohols. In: The pharmacological basis of therapeutics. Goodman, L. S. and Goodman, A. [eds]. Macmillan Publishing Co., Inc. pp 137 - 151.

Spracklen, F.H.N. (1984). Malaria prophylaxis. Part I. S. Af. Med. J. 65(26): 1037-1041.

Tripathi, K. D. [1998]. Essentials of medical pharmacology [ $4^{\text {th }}$ Edition]. Jaypee Brothers Medical Publishers [P] Ltd. New Delhi.

Trojan, H.J. (1982). Augenschaden bei Langzeitprophylaxe der malaria mit chloroquine. Klin Monatsbl Augenheilkd. 180(3). 223-226.

White, N.J. [1985]. Clinical pharmacoknietics of antimalarial drugs. Chin. Pharmacokniet, 10. 187-215 